\title{
Presentación del número monográfico de la revista Aldaba dedicado a las jornadas de psicología
}

\author{
Soledad Ballesteros Jiménez \\ Directora de las Jornadas
}

Este número monográfico de la Revista Aldaba recoge una serie de Conferencias pronunciadas en el Salón de Actos del Centro Asociado de la UNED de Melilla durante los días 26, 27 y 28 de octubre de 1987, así como al solemne acto de inauguración del curso académico 1987-1988 que tuvo lugar el día 28 de octubre a las 12 de la mañana.

El Centro Asociado de Melilla me pidió el pasado mes de julio que organizara unas Jornadas de Psicología que debían celebrarse al comienzo del curso académico 19871988 como complemento a las enseñanzas regladas de Psicología que se imparten en ese centro universitario. Dichas Jornadas llevaron el título "Pasado. Presente y Futuro de la Psicología" e intentaron dar una visión de la Psicología desde sus comienzos como disciplina científica, hasta sus posibles desarrollos futuros, pasando por el tratamiento más actual de algunos temas importantes dentro de esta disciplina académica.

Como directora de las Jornadas, estoy profundamente agradecida a todas aquellas personas que han hecho posible su celebración. Agradezco sinceramente la colaboración prestada a los profesores que han participado en este curso, sin ella, el éxito de las Jornadas no hubiera sido posible. También agradezco a las autoridades del Centro Asociado de la UNED de Melilla: al Presidente del Patronato, Excmo. Sr. Alcalde de Melilla, D. Gonzalo Hernández; a su Director, D. Ramón Gavilán; a su Secretario, D. José Mejías; y a la Coordinadora de estas Jornadas, $D^{\mathbf{a}}$ Teresa Rizo, Profesora-Tutora, que pensarán en mí a la hora de organizar las mismas. También es de agradecer la libertad que me dieron para elegir la temática y los Conferenciantes. Y por último, no podemos dejar de mencionar al personal del Centro por su eficaz colaboración que hizo más fácil y agradable nuestra tarea y nuestra estancia en Melilla. A todos ellos les damos las gracias desde estas páginas de la Revista Aldaba.

El Ciclo constó de 5 Conferencias de una hora de duración, seguidas de coloquio y de una Mesa Redonda sobre "Los Nuevos Planes de Estudio de Psicología".

La primera Conferencia de las Jornadas fue pronunciada por el profesor D. José Luis Pinillos, Catedrático de Psicología, Profesor Emérito de la Facultad de Filosofía y Ciencias de la Educación de la Universidad Complutense de Madrid y Premio Principe de Asturias de Humanidades. El título de su disertación fue "La Psicohistoria y el 
Naturalismo Psicológico". Este es un tema que preocupa y apasiona al profesor Pinillos, maestro de maestros de la Psicología española, y que fue escuchado con atención por la audiencia que llenaba el Salón de Actos del Centro Asociado de Melilla.

La segunda Conferencia fue pronunciada por el profesor D. José Luis Fernández Trespalacios, Catedrático de Psicología General y Director del Departamente de Psicología Básica de la UNED. El título de su Conferencia fue "El Conexionismo", tema ciertamente nuevo en España y de gran actualidad en Estados Unidos como lo demuestra el hecho de que en dos reuniones a las que hemos asistido recientemente, celcbradas en Seattle del 5 al 8 de noviembre, la de la Society for Computers in Psychology y el 28th Meeting of the Psychonomic Society, el tema del conexionismo fuc ampliamente tratado contando con sesiones específicas que tuvieron gran éxito a juzgar por el número de personas que siguieron las ponencias. Destacados impulsores del conexionismo como McClelland y Schneider participaron en las mesas dedicadas a este tema y presentaron el softwere que están desarrollando para simular en el ordenador algunos de los modelos conexionistas.

Las dos conferencias impartidas el martes día 27 de Octubre fueron pronunciadas por el profesor Juan Mayor y por la profesora Soledad Ballesteros. El profesor Juan Mayor es Catedrático de Pensamiento y Lenguaje y Director del Departamento de Psicología Básica (Procesos Cognitivos) de la Facultad de Psicología de la Universidad Complutense de Madrid. El título de su Conferencia fue "Unidad y Diversidad en la Psicología". A lo largo de su intervención, el profesor Mayor planteó el tema de si debe hablarse de una Psicología o por el contrario, lo que existen son múltiples psicologías. La Psicología es una ciencia uniparadigmática, o por el contrario, la Psicología es una ciencia multiparadigmática. Estos y muchos otros aspectos importantes fueron tratados en esta conferencia de una manera sumamente interesante.

La segunda conferencia de la tarde fue impartida por la profesora que escribe estas líncas, Soledad Ballesteros, profesora Titular del Departamente de Psicología Básica de la UNED. El tema de la intervención fue "Psicología Básica y Psicología Aplicada". En ella intentamos contraponer los dos paradigmas, el de la Psicología como ciencia, propio de la Investigación Básica y el de la tecnología, propio de la Psicología Aplicada. La conferencia terminó proponiendo un plan de acción para la reforma de la investigación básica y la investigación aplicada.

El miércoles día 28, el profesor Helio Carpintero pronunció la última conferencia del ciclo, cuyo título fue "Psicología Española: Conocimiento y Profesión". El profesor Carpintero es Catedrático de Historia de la Psicología y Decano de la Facultad de Psicología de la Universidad de Valencia y acaba de volver de la Universidad de California, Los Angeles, dónde ha pasado una temporada realizando una investigación que pronto se va a publicar en castellano y en inglés. En su intervención, presentó una interesante historia de los orígenes de la Psicología española a través de sus profesores e investigadores más destacados e incidió en la importancia de la Psicología como conocimiento susceptible de aplicación. También se refirió a la atracción que esta ciencia ha ejercido sobre los jóvenes estudiantes que ha hecho que se hayan interesado masivamente por ella.

Las Jornadas de Psicología terminaron con una Mesa Redonda sobre un tema de candente actualidad para profesores y alumnos de Psicología, el de los Nuevos Planes 
de Estudio de Psicología. En dicha Mesa Redonda participaron los cinco conferenciantes y la profesora María Victoria del Barrio, Profesora Titular del Area de Personalidad e Intervención de la Facultad de Psicología de la Universidad de Valencia.

Coincidiendo con las Jornadas, el día 28 a las 12 de la mañana fue inaugurado solemnemente el curso académico 1987-1988 en el Centro Asociado de la UNED de Melilla. El acto académico estuvo presidido por el Excmo. Sr. Vicerrector de Asuntos Exteriores de la UNED, D. Juan Antonio Gimeno Ullastres y los Drs. José Luis Pinillos, Helio Carpintero, José Luis Fernández Trespalacios, Juan Mayor, Soledad Ballesteros y María Victoria del Barrio, todos ellos ataviados con el traje académico, el Excmo. Sr. Alcalde y autoridades de Melilla, y el Director del Centro Asociado, D. Ramón Gavilán. El Orfeón Melillense "Padre Vitoria", dirigido por D. Mariano Salgado, interpretó el "Gaudeamus Igitur".

El director del centro, D. Ramón Gavilán, inició el acto académico exponiendo las características especiales de la Universidad a Distancia y señalando tanto sus rasgos comunes con las demás universidades como sus características propias. A continuación, el profesor José Luis Pinillos pronunció la lección magistral del Curso académico 1987-1988, titulada "El Futuro de la Modernidad". Después, el Alcalde de Melilla, D. Gonzalo Hernández, felicitó a los estudiantes del Centro Asociado y a los licenciados que habian terminado su carrera en dicho Centro durante los dos últimos años, a los que se les entregó un Diploma firmado por el Sr. Alcalde en su calidad de Presidente del Patronato y por el director del Centro, D. Ramón Gavilán. Finalmente, el Sr. Vicerrector declaró inaugurado el curso académico 1987-1988. 